08

\title{
Анализ свойств дегидрохлорированных пленок поливинилхлорида
}

\author{
(C) В.И. Крыштоб, С.И. Расмагин \\ Институт общей фризики им. А.М. Прохорова РАН, \\ 119991 Москва, Россия \\ e-mail: rasmas123@ya.ru
}

(Поступило в Редакцию 30 мая 2016 г. В окончательной редакции 3 октября 2016 г.)

Проведено исследование влияния времени термолиза (термодеструкции) на спектры поглощения, удельное сопротивление и концентрацию дырок частично дегидрохлорированных поливинилхлоридных пленок. Определено количество сопряженных двойных связей углерода в пленках в зависимости от времени термолиза.

DOI: 10.21883/JTF.2017.11.45130.1907

\section{Введение}

Электрофизические и оптические свойства пленок поливинилхлорида, полученных в результате термодеструкции, интенсивно исследуются в последнее время [1-6]. Представляется интересным проведение более тщательного исследования влияния времени термолиза на оптические спектры поглощения и удельное сопротивление термически дегидрохлорированных пленок с целью создания проводящей и прозрачной в видимом диапазоне полимерной пленки.

\section{Экспериментальная часть}

Для получения образцов в виде пленок термически дегидрохлорированного поливинилхлорида в качестве исходного материала брали чистый поливинилхлорид (ПВХ) марки С-7058М в растворе ацетофенона. В пробирке в растворителе ацетофеноне растворили порошок (гранулы) ПВХ в соотношении $100 \mathrm{ml}$ ацетофенона и $4 \mathrm{~g}$ ПВХ. Пробирку с полученным раствором помещали в термостат, где проводили процесс термолиза при температуре $t=190^{\circ} \mathrm{C}$ в течение 40-740 min. Далее растворы заливали в чашки Петри диаметром $3.5 \mathrm{~cm}$ и подвергали сушке при температуре $95^{\circ} \mathrm{C}$ в течение $48 \mathrm{~h}$. В результате получали набор дегидрохлорированных ПВХ пленок толщиной 20-22 $\mu \mathrm{m}$.

\section{Результаты и обсуждение}

Для исходной ПВХ пленки и всех вышеупомянутых термически дегидрохлорированных ПВХ пленок в диапазоне 450-850 nm были получены спектры поглощения (см. рисунок) с помощью спектрометра SpectraSuite USB2000 ${ }^{+}$и вольфрамовой лампы LS-1 в качестве источника света. Из графиков на рисунке видно, что спектры поглощения для пленки чистого ПВХ и термически дегидрохлорированной пленки 1 (термолиз $40 \mathrm{~min}$ ) совпадают в диапазоне длин волн
400-850 nm, т.е. общее число образованных сопряженных двойных связей углерода $-\mathrm{C}=\mathrm{C}-$ в макромолекуле сополимера ПВХ-ПАЦ (где ПАЦ - полиацетилен) незначительно. Спектр пленки 2 (термолиз $120 \mathrm{~min}$ ) практически совпадает со спектром чистой пленки ПВХ в диапазоне длин волн 550-800 nm и проходит чуть выше в диапазоне $400-550 \mathrm{~nm}$, т.е. общее число образованных сопряженных двойных связей углерода $-\mathrm{C}=\mathrm{C}-$ в макромолекуле сополимера ПВХ-ПАЦ незначительно выросло. Отметим, что резкое увеличение оптической

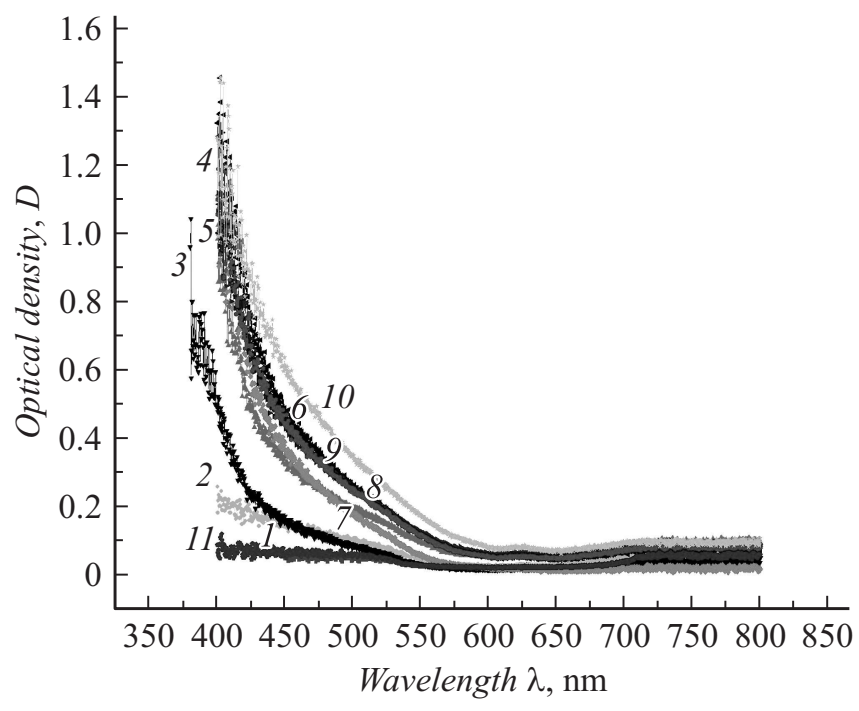

Обозначения для спектров поглощения термически дегидрохлорированных ПВХ пленок в зависимости от длины волны излучения. 1 - дегидрохлорированный ПВХ образец термолиз $40 \mathrm{~min}, 2$ - дегидрохлорированный ПВХ образец термолиз $120 \mathrm{~min}, 3$ - дегидрохлорированный ПВХ образец термолиз $320 \mathrm{~min}, 4$ - дегидрохлорированный ПВХ образец термолиз $360 \mathrm{~min}, 5$ - дегидрохлорированный ПВХ образец термолиз $420 \mathrm{~min}, 6$ - дегидрохлорированный ПВХ образец термолиз $480 \mathrm{~min}, 7$ - дегидрохлорированный ПВХ образец термолиз $520 \mathrm{~min}, 8$ - дегидрохлорированный ПВХ раствор термолиз $580 \mathrm{~min}, 9$ - дегидрохлорированный ПВХ раствор термолиз $640 \mathrm{~min}, 10$ - дегидрохлорированный ПВХ образец термолиз $740 \mathrm{~min}, 11$ - чистый ПВХ образец. 
Зависимости концентрации дырок проводимости $p\left(\mathrm{~cm}^{-3}\right)$ и количества сопряженных двойных связей углерода $N_{-\mathrm{C}=\mathrm{C}-}$ от времени проведения термолиза $t(\mathrm{~min})$ и удельное сопротивление пленок $\left(\rho_{v}, \Omega \cdot \mathrm{cm}\right)$

\begin{tabular}{c|c|c|c|c|c}
\hline$t, \min$ & 40 & 120 & 420 & 640 & 740 \\
\hline$p, \mathrm{~cm}^{-3}$ & $2 \cdot 10^{8}$ & $3 \cdot 10^{10}$ & $1 \cdot 10^{11}$ & $3 \cdot 10^{11}$ & $6 \cdot 10^{11}$ \\
\hline$N_{-\mathrm{C}=\mathrm{C}-}$ & $3 \cdot 10^{17}$ & $1.2 \cdot 10^{18}$ & $6 \cdot 10^{18}$ & $8.4 \cdot 10^{18}$ & $11 \cdot 10^{18}$ \\
\hline$\rho_{v}, \Omega \cdot \mathrm{cm}$ & $3 \cdot 10^{15}$ & $2 \cdot 10^{13}$ & $6 \cdot 10^{12}$ & $2 \cdot 10^{12}$ & $1.1 \cdot 10^{12}$
\end{tabular}

плотности $D$ происходит при времени термолиза $320 \mathrm{~min}$ (пленка 3) в диапазоне длин волн 400-550 $\mathrm{nm}$. Для пленки 4 (термолиз $360 \mathrm{~min}$ ) спектр поглощения лежит еще выше, чем для пленки 3. Но при увеличении времени термолиза с $420 \mathrm{~min}$ до $740 \mathrm{~min}$ спектры поглощения пленок 5-9 в диапазоне 400-550 nm близки друг к другу, т.е. оптическая плотность практически не растет с увеличением времени термолиза. И, наконец, при времени термолиза $740 \mathrm{~min}$ величина оптической плотности пленки 10 выросла по сравнению с предыдущими пленками. В целом, если сравнивать пленку 11 (чистый ПВХ) и пленку 10 термически дегидрохлорированного ПВХ с максимальным временем термолиза $740 \mathrm{~min}$, величина оптической плотности при длине волны $410 \mathrm{~nm}$, которую считаем характерной границей полосы поглощения, увеличилась более чем в 12 раз. То есть в результате термического дигидрохлорирования в течение $740 \mathrm{~min}$ количество сопряженных двойных связей углерода $-\mathrm{C}=\mathrm{C}-$ выросло более, чем на порядок величины. Для того, чтобы узнать, насколько уменьшилось объемное удельное сопротивление некоторых из этих пленок, нами было измерено удельное сопротивление пленок (при температуре $t=24^{\circ} \mathrm{C}$ ) с помощью установки, описанной в [3].

Из таблицы видно, что удельное сопротивление, например, пленки 10 в результате термического дигидрохлорирования в течение $740 \mathrm{~min}$ уменьшилось почти в 2700 раз. Поскольку концентрация акцепторной примеси $\mathrm{Cl}$ в сополимере ПВХ-ПАЦ значительно превосходит концентрации других вероятных акцепторных примесей, можно полагать, что количество электрически активных сопряженных двойных связей углерода $-\mathrm{C}=\mathrm{C}-$ также значительно выросло. Так как донорные примеси, такие как $\mathrm{Na}, \mathrm{K}, \mathrm{B}$, в наших пленках практически не обнаружены, то электронной проводимостью в сравнении с дырочной можно пренебречь. Поэтому оценим концентрацию дырок в рассмотренных выше пленках исходя из стандартной формулы

$$
p=1 /\left(\rho_{v} \mu_{p} e\right)
$$

где $p$ - концентрация дырок $\left(\mathrm{cm}^{-3}\right), \rho_{v}-$ объемное удельное сопротивление пленок, $e-$ заряд $1.6 \cdot 10^{-19} \mathrm{C}$, $\mu_{p}$ - подвижность дырок $\left(\mathrm{cm}^{2} / \mathrm{V} \cdot \mathrm{s}\right)$. Все полученные пленки по величине удельного сопротивления можно отнести к классу малопроводящих, поэтому принимаем подвижность порядка $\mu_{p}=10^{-5}\left(\mathrm{~cm}^{2} / \mathrm{V} \cdot \mathrm{s}\right)$. Из таблицы видно, что увеличение времени термолиза в 18 раз приводит к росту дырок в 3000 раз, т.е. концентрация электрически активных цепочек (полиеновые структуры, встроенные в макромолекулы ПВХ) сопряженных двойных связей углерода сильно зависят от времени термолиза.

Зная массы пленок $29 \cdot 10^{-3}-61 \cdot 10^{-3}$ g, получим число звеньев ПВХ в каждой пленке: $1-N_{ч} 1=2.8 \cdot 10^{20}$, $2-N_{432}=3.8 \cdot 10^{20}, 5-N_{435}=5.5 \cdot 10^{20}, 9-$ $N_{439}=5 \cdot 10^{20}, 10-N_{43} 10=5.8 \cdot 10^{20}$. Известно, что выделение в процессе термического дегидрохлорирования каждой молекулы $\mathrm{HCl}$ приводит, как правило, к образованию одной сопряженной двойной связи углерода $\mathrm{C}=\mathrm{C}-$ (так как число возникающих сопряженных двой-

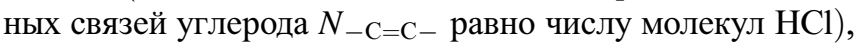
поэтому можно записать [7,8]:

$$
N_{-\mathrm{C}=\mathrm{C}-}=N_{\mathrm{HCl}}=N_{\mathrm{ч}} V_{\mathrm{HCl}}(\mathrm{mol} \mathrm{HCl} / \mathrm{mol} \mathrm{BXs}) t,
$$

где $N_{\mathrm{HCl}}$ - число молекул $\mathrm{HCl}$, выделенных в процессе термического дегидрохлорирования, $N_{43}-$ число всех звеньев ПВХ в пленке, $V_{\mathrm{HCl}}-$ скорость термического дегидрохлорирования (при наших условиях $V_{\mathrm{HCl}}=44 \cdot 10^{-8}(\mathrm{~mol} \mathrm{HCl} / \mathrm{mol}$ ПВХ $\left.) \cdot 1 / \mathrm{s}\right), t$ - время проведения термического дегидрохлорирования в секундах, ВХ - винилхлорид (мономерное звено ПВХ).

Сделаем оценку количества сопряженных двойных связей углерода в пленках сополимера ПВХ-ПАЦ. Используя данные $\mathrm{N}_{\text {чз }}$ - число всех звеньев ПВХ в пленке, $V_{\mathrm{HCl}}-$ скорость термического дегидрохлорирования и формулу (2), получаем оценки количества сопряженных двойных связей углерода $N_{-\mathrm{C}=\mathrm{C}-}$ в пленках при разных временах термического дегидрохлорирования. Результаты показаны в таблице. Из данных таблицы хорошо видно, как с увеличением времени термолиза растет число сопряженных двойных связей углерода. Если взять самое малое и самое большое время термолиза, то увеличение времени термолиза в 18 раз приводит к росту количества сопряженных двойных связей углерода

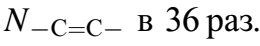

\section{Заключение}

В результате анализа спектров поглощения и определения удельных сопротивлений термически дегидрохлорированных пленок ПВХ приходим к следующим выводам.

1. Увеличение оптической плотности (коэффициента поглощения) пленок сополимера ПВХ-ПАЦ связано с

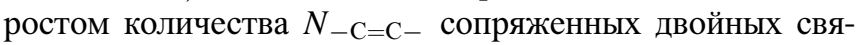
зей углерода $-\mathrm{C}=\mathrm{C}-$. Количество сопряженных двойных связей углерода $-\mathrm{C}=\mathrm{C}-$ в пленках увеличивается с ростом температуры термолиза и варьируется в диапазоне $N_{-\mathrm{C}=\mathrm{C}-}=3 \cdot 10^{17}-1 \cdot 10^{19}$. При этом сопряженные 
двойные связи углерода увеличиваются нелинейно с ростом времени процесса термолиза.

2. Концентрации дырок в термически дегидрохлорированных пленках зависят от времени термолиза и лежат в интервале $p=2 \cdot 10^{8}-6 \cdot 10^{11}\left(\mathrm{~cm}^{-3}\right)$.

\section{Список литературы}

[1] Barford $W$. Electronic and Optical Properties of Conjugated Polymers, Clarendon, Oxford, 2005.

[2] Wan M. Conducting Polymers with Micro or Nanometer Structure. Springer, 2008.

[3] Крыштоб В.И., Власов Д.В., Миронов В.Ф., Апресян Л.А., Власова Т.В., Расмагин С.И., Кураташвили З.А, Соловский А.А. // Электротехника. 2014. № 5. С. 60-64.

[4] Власов Д.В., Апресян Л.А., Власова Т.В., Крыштоб В.И., Расмагин С.И. // Высокомол. соед. Сер. А. 2015. Т. 57. № 3. C. $1-5$.

[5] Крыштоб В.И., Власов Д.В., Миронов В.Ф., Апресян Л.А., Власова Т.В., Расмагин С.И., Кураташвили З.А, Соловский A.A. // Электротехника. 2015. № 8. С. 39-42.

[6] Rasmagin S.I., Krasovskii V.I., Vlasov D.V., Aprecyan L.A., Vlasova T.V., Kryshtob V.I., Feofanov I.N., Kazaryan M.A. // Proc. SPIE. 2015. Vol. 9810.

[7] Минскер К.С., Абдуллин М.И., Гизатуллин Р.Р., Заиков Г.Е. // Высокомолек. соед. 1985. Т. А XXVII. № 7. C. $1428-1433$.

[8] Минскер К.С., Федосеева Г.Т. Деструкция и стабилизация поливинилхлорида. М.: Химия, 1972. С. 1-424. 